\title{
An Empirical Study of Teacher's Behavioral Intention to Use Online Teacher Communities
}

\author{
Ming-Chou Liu* \\ Graduate Institution of Education \\ National Dong Hwa University \\ Hualien, Taiwan \\ liu@mail.ndhu.edu.tw \\ *Corresponding author \\ Kuan-Hung Wang \\ Graduate Institution of Science Education \\ National Dong Hwa University \\ Hualien, Taiwan \\ hlhi0009@ hotmail.com
}

\author{
Wen-Chung Chan \\ Graduate Institution of Education \\ National Dong Hwa University \\ Hualien, Taiwan
}

\author{
Jian-Hong Pan \\ Graduate Institution of Education \\ National Dong Hwa University \\ Hualien, Taiwan \\ imihi.hiffy@msa.hinet.net
}

\begin{abstract}
This study aims to investigate factors that contribute to teacher's behavioral intention to use online communities. To answer the research questions, the survey instrument--The Teacher's Behavioral Intention to Use the Online Community Questionnaire is designed and performed on simple random samples. The collected data is analyzed using descriptive statistics and regression analysis. The results of this study show that all the research hypotheses are supported by regression analysis except for the relationship between Self-efficacy and Attitude; Collective efficacy and Behavioral Intention; Subjective Norm and Behavioral Intention, respectively. Finally, this study raises implications and provides suggestions.
\end{abstract}

Keywords-online teacher communities; behavioral intention; teacher professional development

\section{RESEARCH BACKGROUND}

Online teacher communities can break through the limitations of time and space, and in particular provide opportunities for professional development of teachers in remote areas or smaller schools. As of the end of September 2012, the Sakizaya Network in Hualien County of Taiwan has seen establishment of 586 sites with a total of 7031 members [1]. Most users are elementary and junior high school teachers in Hualien County; the objective is to foster an instructional team that has energy for teaching, research, and sharing through the operations of the online teacher communities. However, teachers are already busy with teaching and their own affairs, thus it is necessary to conduct an in-depth exploration of their motives, attitudes, and influential factors in their active usage of online teacher communities. This study attempts to combine Theory of Planned Behavior (TPB) [2] and Technology Acceptance Model (TAM) [3] as the basic research model, by analyzing behavioral intentions of elementary and junior high school teachers in Hualien County in participating in the Sakizaya Network, to construct the model for "behavior intentions to use online teacher communities." The study will explore whether the model relationships from literature are found in the Sakizaya Network can be established, in order to understand the thoughts and influential factors for users. Thus, it is possible to elevate the intention of participation in online teacher communities and draw more teachers to become involved, thereby promoting collaborative learning and development of professional knowledge among teachers.

\section{A. Online Teacher Communities and Teacher Professional Development}

Online teacher communities are not constrained by spatial and temporal limitations of physical communities, and can provide for synchronous and asynchronous sharing and discussion, further overcoming the differences between schools or between the rural and urban, so that teachers with common beliefs can interact, observe, and help each other through the online communities, in turn promoting professional development for each member teacher. The formation of online teacher communities has its own unique characteristics, and the formation and conversion of knowledge also differs from that in physical communities. The study by Liu and Chang pointed out that collective efficacy is an important factor in the development of online teacher communities [4]. Bandura believed that individuals are unable to achieve various outcomes, thus it is necessary to rely on collective cooperation. Collective efficacy refers to how group members judge the abilities of their own group, or the group's shared beliefs about whether it can successfully complete specific goals [5]. Kao, $\mathrm{Wu}$, and Tsai found that the online self-efficacy and behavioral beliefs of teachers about online learning can effectively predict the motivation for teacher professional development [6]. This shows that self-efficacy is an important factor in the development of online teacher communities, thus self-efficacy and collective efficacy will also be incorporated as variables to be explored. 


\section{B. Theoretical Integration of Teachers' Usage Intentions toward Online Communities}

The Theory of Planned Behavior not only asserted that behavioral intention would be influenced by attitudes and subjective norms, but also incorporated the construct of "perceived behavioral controls" to increase the overall explanatory power [2]. Perceived behavioral controls reflect an individual's past experiences and expected obstacles; thus, intrinsic and extrinsic factors influence personal behavioral controls. Davis proposed the Technology Acceptance Model to explore behavioral models and acceptance in individual usage of information technology. The correlations among perceived usefulness, perceived ease of use, attitudes, behavioral intentions, and external variables are used to observe and interpret the technology usage behaviors of users. Technology Acceptance Model theory shows that perceived usefulness and perceived ease of use in information technology are the two main determining factors of usage behavior intentions [3]. At the same time, perceived ease of use would also have a positive effect on perceived usefulness, in turn affecting the behavioral intentions of usage. Taylor and Todd integrated TPB and TAM theory to incorporate the two variables of subjective norms and perceived behavioral controls into the Technology Acceptance Model, which found a good fit for explaining the behavior of using new technology [7]. Yu Taiquei also believed that TPB and TAM can be applied in the prediction and analysis of behavioral intentions of users to explore the reasons for the acceptance or rejection of a certain item in information technology in order to improve the acceptance for the information technology item; he also pointed out that selfefficacy has been seen by social cognitive scholars as a type of perceived behavioral control, which is broader and more comprehensive than the control belief proposed by Ajzen [8]. Baker found that there is a significant correlation between collective efficacy and self-efficacy [9]. Chen used literature analysis to explore the relationship between the self-efficacy and collective efficacy of teachers, finding that collective efficacy can be used to predict significant positive self-efficacy in teachers [10]. Skaalvik and Skaalvik also found that the collective efficacy of Norwegian teachers can significantly predict their self-efficacy [11]. Chen and Chang discovered that expectation of collective efficacy can have significant positive effects on "the behavioral intentions of participating in collective action" [12].

Therefore, this study uses TPB and TAM as basic research models. Then, self-efficacy replaces perceived behavioral controls, and the dimension of collective efficacy is added to deduce the behavior intentions in using online teacher communities at the Sakizaya Network, proposing the following hypotheses:

H1: The "self-efficacy" of teachers would affect their "attitude" toward participation in online teacher communities.

H2: The "self-efficacy" of teachers would affect their "behavioral intentions" toward participation in online teacher communities.

H3: The "collective efficacy" of teachers would affect their "self-efficacy" toward participation in online teacher communities.
H4: The "collective efficacy" of teachers would affect their "behavioral intentions" toward participation in online teacher communities.

H5: The "subjective norms" of teachers would affect their "attitude" toward participation in online teacher communities.

H6: The "subjective norms" of teachers would affect their "behavioral intentions" toward participation in online teacher communities.

H7: The "perceived usefulness" of teachers would affect their "attitude" toward participation in online teacher communities.

H8: The "perceived ease of use" of teachers would affect their "attitude" toward participation in online teacher communities.

H9: The "perceived ease of use" of teachers would affect their "perceived usefulness" toward participation in online teacher communities.

H10: The "attitude" of teachers would affect their "behavioral intentions" toward participation in online teacher communities.

\section{METHOD}

\section{A. Research Subjects}

The research subjects are primarily elementary and junior high school teachers in Hualien who participate in the Sakizaya Network. Purposive sampling was used to select members who have registered as elementary and junior high school teachers in Hualien from the database, removing the teachers who have taken the pretest. The online questionnaire for the official testing (http: //teacher.hlc.edu.tw/101act/Quest/) was sent out via E-mail.

\section{B. Research Tools}

The "The Teacher's Behavioral Intention to Use the Online Community Questionnaire" used in this study primarily referred to the questionnaires in past literature [11], which were then compiled and modified by the researchers. Three experts conducted evaluation, item analysis, factor analysis, reliability analysis, and pretest. In this scale, $\alpha$ coefficients of the various dimensions are in the range of .83-.94, the $\alpha$ coefficient of the overall scale is .96 , which shows that the questionnaire has a high level of internal consistency, and is a questionnaire with good reliability.

\section{Research Framework}

The framework for this study is developed based on the motives, purposes, and literature review in this study. This study contains seven dimensions, which are "perceived ease of use," "perceived usefulness," "attitude," "subjective norms," "self-efficacy," "collective efficacy," and "behavioral intentions"; the research framework is shown in Fig. 1. This study uses the four variables of "self-efficacy" "perceived usefulness," "attitude," and "behavioral intentions" as the criterion variables, and regression analysis is conducted based on the research framework, these are: simple linear regression analysis of "collective efficacy" to "self-efficacy," simple linear regression analysis of "perceived ease of use" to 
"perceived usefulness," multiple regression analysis of "attitude," and multiple regression analysis of "behavioral intentions," in order to understand the causal relationships among different variables.

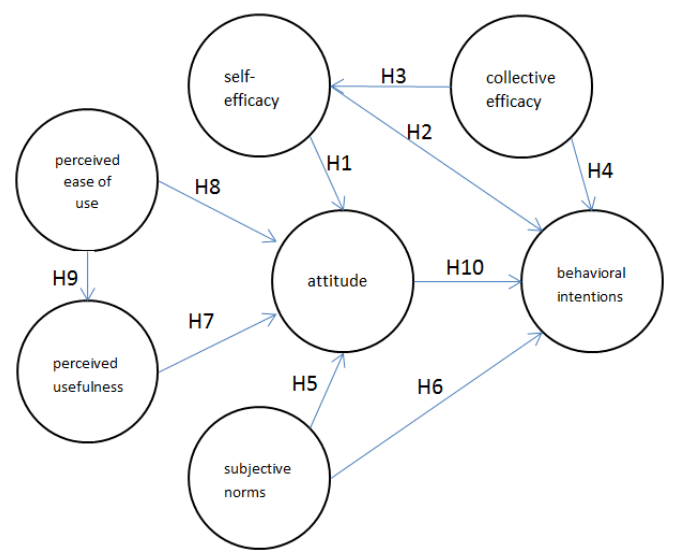

FIGURE I. RESEARCH FRAMEWORK

\section{RESULTS}

This study is divided into two simple linear regression analyses and two multiple regression analyses, which explores the four criterion variables of "self-efficacy," "perceived usefulness," "attitude," and "behavioral intentions.". The Enter method is selected, so that all predictor variables for the multiple regression analysis enter the regression equation .

\section{A. Simple Linear Regression Analysis}

Simple linear regression analysis is conducted in two instances for (1) "collective efficacy" to "self-efficacy" and (2) "perceived ease of use" to "perceived usefulness," in order to understand the extent to which collective efficacy can predict self-efficacy and perceived ease of use can predict perceived usefulness. Results of analysis show: the correlation coefficient of "collective efficacy" to "self-efficacy" is .72, the squared correlation coefficient is .52 , meaning the dimension of "collective efficacy" can explain $52 \%$ of the variance in "selfefficacy". In this regression model, "collective efficacy" has a significant positive influence on "self-efficacy." in addition, the correlation coefficient of "perceived ease of use" to "perceived usefulness" is .75, the squared correlation coefficient is .56; this means that the dimension of "perceived ease of use" can explain $56 \%$ of the variance in "perceived usefulness." In this regression model, "perceived ease of use" has a significant positive influence on "perceived usefulness."

\section{B. Multiple Regression Analysis}

This study first conducts multiple regression analysis of "attitude," in which self-efficacy, subjective norms, perceived ease of use, and perceived usefulness are the predictor variables, attitude is the criterion variable, for general multiple regression analysis, in order to understand the extent to which the different variables can predict attitude. Table 1 shows that: the four predictor variables, "self-efficacy," "subjective norms," "perceived ease of use," and "perceived usefulness" have the correlation coefficient of .87 with "attitude," the squared correlation coefficient is .76 , meaning that the four predictor variables can explain $76 \%$ of variance in "attitude." The $\beta$ values of all four predictor variables are all positive, meaning that they exert positive effects on "attitude." In the regression model, the three predictor variables, "subjective norms," "perceived ease of use," and "perceived usefulness" can significantly affect and predict "attitude." Among the three dimensions that significantly affect prediction, the explained variances ranked by size are, from largest to smallest, "perceived usefulness," "perceived ease of use," and "subjective norms." Since "self-efficacy" did not reach the level of significance, it means that it only explains a small amount of variance in "attitude."

TABLE I. SUMMARY OF MULTIPLE REGRESSION ANALYSIS OF SELF-EFFICACY, SUBJECTIVE NORMS, PERCEIVED EASE OF USE, AND PERCEIVED USEFULNESS TO ATTITUDE

\begin{tabular}{ccccc}
\hline $\begin{array}{c}\text { predictor } \\
\text { variable }\end{array}$ & $\mathrm{B}$ & $\begin{array}{c}\text { Standard } \\
\text { error }\end{array}$ & Beta $(\beta)$ & T value \\
\hline intercept & .63 & .96 & & .66 \\
self-efficacy & .10 & .07 & .12 & 1.37 \\
$\begin{array}{c}\text { collective } \\
\text { efficacy }\end{array}$ & .15 & .05 & .19 & $2.70^{* * *}$ \\
$\begin{array}{c}\text { subjective } \\
\text { norms }\end{array}$ & .30 & .08 & .33 & $3.87^{* * *}$ \\
attitude & .40 & .10 & .39 & $3.79^{* * * *}$ \\
\hline $\mathrm{R}=.87$ & $\mathrm{R}^{2}=.76$ & Adjusted $\mathrm{R}^{2}=.74$ & $\mathrm{~F}=58.15^{* * *}$ \\
\hline
\end{tabular}

Table 2 shows that: the four predictor variables of "selfefficacy," "collective efficacy," "subjective norms," and "attitude" have a .85 correlation coefficient to "behavioral intentions," the squared correlation coefficient is .72, which means that the four predictor variables can explain $72 \%$ of variance in "behavioral intentions." The $\beta$ values of all four predictor variables are all positive, meaning that they exert positive effects on "behavioral intentions." In the regression model, the two predictor variables of "self-efficacy" and "attitude" can significantly affect and predict "behavioral intentions." Among the two dimensions that significantly affect prediction, the explained variances ranked by size are, from largest to smallest, "attitude" and "self-efficacy." Since "collective efficacy" and "subjective norms" did not reach the level of significance, it means that they only explain a small amount of variance in "behavioral intentions."

TABLE II. SUMMARY OF MULTIPLE REGRESSION ANALYSIS OF SELF-EFFICACY, COLLECTIVE EFFICACY, SUBJECTIVE NORMS, AND ATTITUDE TO BEHAVIORAL INTENTIONS

\begin{tabular}{|c|c|c|c|c|}
\hline $\begin{array}{c}\text { predictor } \\
\text { variable }\end{array}$ & B & $\begin{array}{l}\text { Standard } \\
\text { error }\end{array}$ & Beta $(\beta)$ & $\mathrm{T}$ value \\
\hline intercept & 1.26 & 1.38 & & .91 \\
\hline self-efficacy & .31 & .11 & .28 & $2.81^{* *}$ \\
\hline $\begin{array}{l}\text { collective } \\
\text { efficacy }\end{array}$ & .03 & .09 & .03 & .34 \\
\hline $\begin{array}{l}\text { subjective } \\
\text { norms }\end{array}$ & .04 & .08 & .04 & .54 \\
\hline Attitude & .91 & .12 & .68 & $7.52 * * *$ \\
\hline $\mathrm{R}=.85$ & $\mathrm{R}^{2}=.72$ & Adjusted $\mathrm{R}^{2}=.71$ & \multicolumn{2}{|c|}{$\mathrm{F}=48.10^{* * * *}$} \\
\hline
\end{tabular}

\section{Regression Analysis of Behavior Intentions to Use Online Teacher Communities}

The four regression analysis $\beta$ values and relevant statistical values are entered into the research framework, to form the 
regression analysis model of behavior intentions to use online teacher communities, as shown in Fig. 2. Among the ten dimensions proposed by this study, other than an absence of significant influence of self-efficacy on attitude, collective efficacy on behavioral intentions, and subjective norms on behavioral intentions, remaining hypotheses received significant support. The study's latent dependent variables have the following explained variance (R2) in the model: "perceived usefulness" is .56, "self-efficacy" is .52, "attitude" is .76, and behavioral intentions is .72 , thus, the four dependent variable constructs in this study all have good explanatory ability.

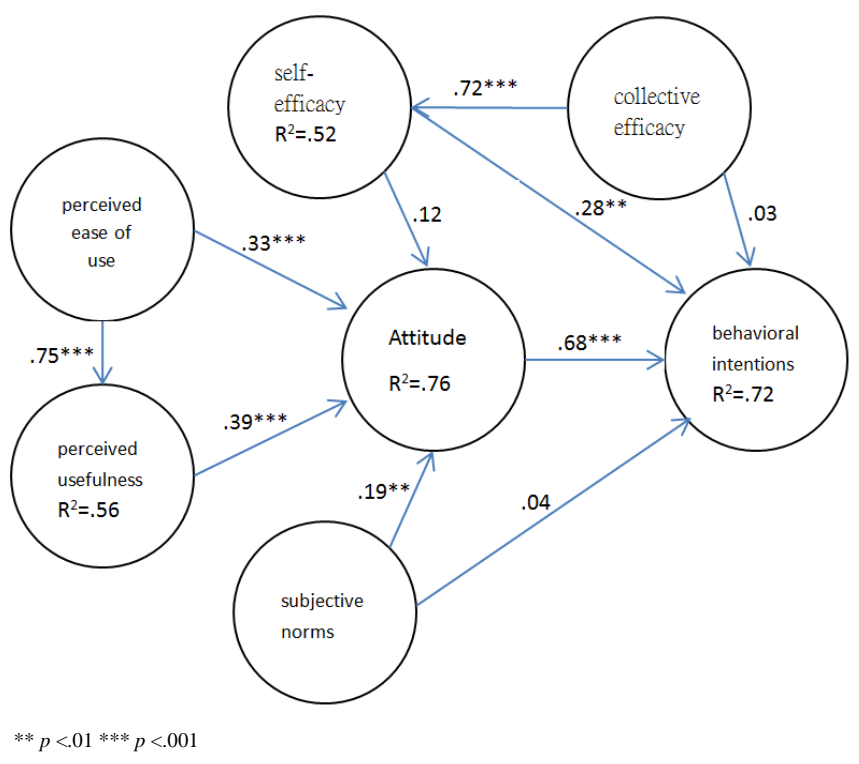

\section{FIGURE II. REGRESSION ANALYSIS MODEL OF BEHAVIOR INTENTIONS TO USE ONLINE TEACHER COMMUNITIES}

\section{DISCUSSION AND CONCLUSION}

This study uses empirical data to analyze usage behavior intentions in the online teacher community of Sakizaya Network. The explanatory power of this research model is in the range of $52 \%-76 \%$, and $72 \%$ of predictive and explanatory power for "behavioral intentions," making it highly ideal. On the whole, the theoretical model of this study combining TAM and TPB has decent explanatory power; empirical data analysis shows that the research model constructed by this study has stability.

Among the ten dimensions proposed, other than no significant relationships between self-efficacy and attitude, collective efficacy and behavioral intentions, and subjective norms and behavioral intentions, the rest all showed significant effect; this results is consistent with theory from literature review. However, this study believes that research subjects are more able to rationally analyze the possible difficulties when participating in Sakizaya Network, as well as to consider personal constraints in time and resources, so that the "selfefficacy" of teachers would not affect their "attitude" in participating in Sakizaya Network. In addition, in physical instructional contexts, teachers usually prepare for instruction on their own, while competitions in the Sakizaya Network also emphasize sharing of individual teachers' instructional videos, therefore, collective efficacy is not a cause of community participation, but it is possible that a sense of collective efficacy arises from participation in the online community. As a result, the "collective efficacy" of teachers would not directly affect their "behavioral intentions" of participating in the Sakizaya Network. Thus, it is possible to use the elevation of collective efficacy to influence self-efficacy, then indirectly create behavioral intentions for using online teacher communities. In addition, subjective norms do not have a direct effect on behavioral intentions, but the research model shows that it can still indirectly affect behavioral intentions through attitude. This study believes that even though teachers have strong subjective wills, and are unlikely to be affected by others in their participation in online teacher communities, peer influence can still significantly change the attitudes of teachers, in turn making them consider usage.

Finally, we suggest that online teacher communities can add online team competition events, and interaction and discussion on the platform can be used to enhance the detailed development of professional knowledge in instructional design for teachers.

\section{REFERENCES}

[1] Sakizaya Network, "Total numbers of members and sites," September 30, 2012, http: //teacher.hlc.edu.tw/index.asp.

[2] I. Ajzen, From intentions to actions : A theory of planned behavior, Action-control: From cognition behavior, Heidelberg: Springer, 1985.

[3] F. D. Davis, "Perceived usefulness, perceived ease of use, and user acceptance of information technology," MIS Quarterly, vol. 13(3), 1989, pp. 319-340.

[4] M.-C. Liu and Y.-S. Chang, "Collaborative Learning Process and Communicative Content Analysis of Web-based Teacher Professional," Curriculum \& Instruction Quarterly, vol. 14 (2), 2011, pp. 30-54.

[5] A. Bandura, Guide for constructing self-efficacy scales, Self-efficacy beliefs of adolescents: Information Age Publishing, 2006, pp. 307-337.

[6] C. P. Kao, Y. T. Wu, and C. C. Tsai, "Elementary school teachers' motivation toward web-based professional development, and the relationship with internet self-efficacy and belief about web-based learning," Teaching and Teacher Education, vol. 27(2), 2011, pp. 406415.

[7] S. Taylor and P. A. Todd, "Assessing IT Usage: The role of prior experience," MIS Quarterly, vol. 19(2), 1995, pp. 561-570.

[8] T.-K. Yu, "An empirical study of web-based learning adoption in the behavioral and cognitive styles," Journal of Education \& Psychology, vol. 29(4), 2006, pp. 687-717.

[9] D. F. Baker, "The development of collective efficacy in small task groups," Small Group Research, vol. 32(4), 2001, pp. 451-474.

[10] C.-W. Chen, "Collective teacher efficacy: Concept, measurement and research," Journal of Educational Practice and Research, vol. 22(2), 2001, pp. 123-150.

[11] E. M. Skaalvik and M. Skaalvik, "Dimensions of teacher self-efficacy and relations with strain factors, perceived collective teacher efficacy, and teacher burnout," Journal of Educational Psychology, vol. 99, 2007, pp. 611-625.

[12] J.-M. Chen and M.-L. Chang, "Effects of Group Relative Deprivation and Collective Efficacy," Journal of Education \& Psychology, vol. 23(1), 2000, pp. 123-146. 